\title{
The role of hepcidin, ferroportin, HCP1, and DMT1 protein in iron absorption in the human digestive tract
}

\author{
Justyna Przybyszewska ${ }^{1}$ Ewa Żekanowska² \\ ${ }^{1}$ Department of Nutrition and Dietetics, Nicolaus Copernicus University in Torun, Collegium Medicum in Bydgoszcz, Poland \\ ${ }^{2}$ Department of Pathophysiology, Nicolaus Copernicus University in Torun, Collegium Medicum in Bydgoszcz, Poland
}

Prz Gastroenterol 2014; 9 (4): 208-213

DOI: $10.5114 / p g .2014 .45102$

Key words: iron, bioavailability, hepcidin, ferroportin, HCP1, DMT1.

Address for correspondence: Justyna Przybyszewska MD, PhD, Department of Nutrition and Dietetics, Collegium Medicum, 3 Dębowa St, 85-626 Bydgoszcz, Poland, phone: +48 5258554 01, fax: +48 5258554 00, e-mail: j.szwarc@wp.pl

\begin{abstract}
Iron is found in almost all foods, so dietary iron intake is related to energy intake. However, its availability for absorption is quite variable, and poor bioavailability is a major reason for the high prevalence of nutritional iron deficiency anaemia. Absorption occurs primarily in the proximal small intestine through mature enterocytes located at the tips of the duodenal villi. Two transporters: Hem Carrier Protein 1 (HCP1) and Divalent Metal Transporter 1 (DMT1) appear to mediate the entry of most if not all dietary iron into these mucosal cells. Absorption is regulated according to the body's needs. The results of studies suggest that iron absorption is regulated by the control of iron export from duodenal enterocytes to the circulating transferrin pool by ferroportin. Hepcidin, a 25-amino acid polypeptide, which is synthesised primarily in hepatocytes, reduces the iron absorption from the intestine by binding to the only known cellular iron exporter, ferroportin, causing it to be degraded. Therefore, hepcidin is now considered to be the most important factor controlling iron absorption.
\end{abstract}

\section{Introduction}

There are two forms of dietary iron: inorganic (ionic, non-haem) and organic (haem) [1], with a higher percentage of the non-haem form in the total dietary pool of iron. On average, haem iron constitutes $40 \%$ of iron in a typical European diet [1]. However, in a vegetarian diet, consisting solely of products of plant origin, the haem form corresponds to only $10-20 \%$ of total iron [1]. Regardless of the form of iron, its absorption takes place in mature enterocytes. The enteric cells reach absorptive maturity during their migration from duodenal crypts towards the apex of the intestinal villus [2]. Two main pathways of absorption of iron from the alimentary tract lumen have been identified and described in detail to date [3]. One of them is associated with haem carrier protein 1 (HCP1), and the other involves divalent metal transporter (DMT1). Moreover, the potential involvement of receptors for ferroproteins, e.g. lactoferrin or phytoferritin, is the subject of extensive research. The presence of lactoferrin receptors (LfRs) is thought to play an important part in the process of iron absorption during the neonatal period [3]. The role of receptors for phytoferritin, an iron-binding compound of plant cells, also merits further research. The results of such studies could potentially improve the parameters of iron metabolism in the populations of developing countries [3]. In a series of papers, Baranowski highlighted the previously undervalued role of mucins in the absorption of nutrients [4-6]. Mucins, from the group of glycoproteins, constitute the main component of mucus synthesised by cells of gastrointestinal mucosa. Under physiological conditions these molecules can bind iron ions (both $\mathrm{Fe}^{2+}$ and $\mathrm{Fe}^{3+}$ ) and form soluble complexes, which can be directly absorbed from the duodenum. According to Baranowski, both haem and lactoferrin receptors, as well as receptors involved in the absorption of iron-glycoprotein complexes, can be present in the duodenal mucosal brush border [4]. This hypothesis seems to be consistent with the results of radioisotope and immunological studies, which revealed the presence of a membrane receptor on the absorption surface of the microvilli. This receptor, from the integrin group, 
displayed an ability to bind iron and transfer it to the inside of the cell [4]. The presence of alkaline $\mathrm{pH}$ in the duodenal content is a prerequisite for the absorption of iron ions by the mucin-integrin system. In clinical conditions with impaired secretory function and/or a shift of acid-base balance towards acidosis, significant disorders of the absorption activity have been observed. Research indicates that acidification of the duodenal content changes the physicochemical properties of mucins, and stimulates the formation of their aggregates and the resultant loss of iron ion-binding capacity [4-6]. Inhibition of iron absorption is a further result of the altered physicochemical properties of mucins.

\section{Absorption of haem iron}

The term "haem iron" refers to iron pool incorporated into the protoporphyrin IX ring. Absorption of this form of iron is markedly more effective than that of the ionic iron. The average bioavailability of haem iron is ca. $20-30 \%$, but can reach up to $50 \%$ when required $[1,3]$. Differences in the bioavailability of various forms of iron suggest differentiation of the absorption mechanisms.

HCP1 (haem carrier protein 1) is a protein enabling transmembrane transport of haem molecules from alimentary tract lumen into enterocyte [7, 8]. Human HCP1 is a highly hydrophobic protein composed of 446 amino acids. It is encoded by the gene located on chromosome 17q11.1. The expression of HCP1 on both the apical membrane of enterocytes and in the plasmatic membrane of enteric cells has been documented [7, 8]. The protein located on the apical membrane consists of nine-transmembrane domains. Although strong expression of HCP1 is typical for the proximal segment of the small intestine (mostly the duodenum), the presence of this protein was also detected in the liver and kidneys. Synthesis of HCP1 is regulated on both pre - and post-translational level $[7,8]$. The expression of HCP1 mRNA is modulated by hypoxia and hypotransferrinaemia. During the post-translational stage, the level of HCP1 is modulated by the concentration of iron in the duodenum [7, 8]. This process is probably associated with the transfer of HCP1 from the apical membrane of enterocyte into its cytoplasm and vice versa. High concentrations of HCP1 in the apical membrane have been observed in iron-deficient mice [7, 8], whereas the opposite phenomenon was documented in iron-overfed animals, in which the expression of this protein was limited mostly to cytoplasm [7, 8].

Inside enterocyte, the haem molecule is catabolised by a microsomal enzyme, haem oxygenase. The products of haem oxygenase-catalysed degradation of haem include bivalent ferrous ions $\left(\mathrm{Fe}^{2+}\right)$, carbon oxide (CO), and biliverdin $\mathrm{IXa}$, which is subsequently reduced to bil- irubin by biliverdin reductase [9]. To date, two different isoforms of haem oxygenase, encoded by two separate genes, have been described in humans [9]. The activity of the first isoform (HO-1) is induced by an array of factors, including cellular stress, reactive oxygen species, haem, thermal shock, UV radiation, nitric oxide (NO), pro-inflammatory cytokines, and heavy metals ( $\mathrm{Cd}$, Co, $\mathrm{Cr}, \mathrm{Cu}, \mathrm{Fe}, \mathrm{Hg}, \mathrm{Ni}, \mathrm{Pd}, \mathrm{Pt}, \mathrm{Sn}$, and $\mathrm{Zn}$ ) [9]. HO-1 protects cells against the cytotoxic and pro-oxidative effects of free haem [9].

The protective mechanism of haem oxygenase-1 is multidirectional and results from the cytoprotective effects of various products of haem degradation. Although the bivalent ferrous ions, released in the course of haem metabolism are involved in the generation of superoxide anion radicals, they also stimulate the synthesis of ferritin (iron-binding protein), which displays antioxidative properties [10].

Another product of haem catabolism, biliverdin, and its metabolite, bilirubin, display strong antioxidative activity associated with the inhibition of free radical-induced damage to lipid membranes and plasma lipoproteins [11]. Furthermore, an interaction between either biliverdin, or between bilirubin and the reactive nitrogen species, e.g. peroxynitrite, has been documented [12]. The cytoprotective effect of carbon oxide is associated with an improved perfusion of tissues, resulting from dilation of blood vessels and an anti-aggregatory effect $[13,14]$. Moreover, CO was found to inhibit the process of cellular apoptosis [15]. While discussing the protective properties of $\mathrm{HO}-1$, it should be emphasised that they strictly correspond to the amount of the active enzyme. A two - to five-fold increase in the activity of HO-1 associated with the protection of cells against toxic effects of oxygen was noted [16]. However, the same study revealed a lack of the protective effect of $\mathrm{HO}-1$ when its activity was increased 15 times [16]. Damage to tissues associated with the overexpression of haem oxygensase- 1 is a result of the fact that all products of haem degradation are toxic at higher concentrations [17]. The toxicity of carbon oxide can be observed already at concentrations slightly exceeding the normal level [17].

The other isoform of haem oxygenase (HO-2) is constantly expressed in cells and plays a pivotal role in the catabolism of haem in absorptive enterocytes [18]. Alternatively, the haem molecule present inside the enterocyte can also be degraded to non-haem iron and bilirubin by HO-1 located in the endoplasmic reticulum [18].

The ionic iron released in the process of haem degradation is further metabolised on the common pathway with non-haem iron. Depending on actual demand, iron ions present inside absorptive enterocytes can be 
either stored as ferritin and eliminated from the organism with exfoliated enterocytes, or are further transported across the basolateral membrane of enterocytes [19].

\section{Absorption of non-haem iron}

Because non-haem (trivalent) iron forms insoluble non-absorbable complexes in alkaline environment, the process of its absorption has to be preceded by the reduction of ferric ion $\left(\mathrm{Fe}^{3+}\right)$ to ferrous ion $\left(\mathrm{Fe}^{2+}\right)$ [3]. This process can involve both dietary nutrients and endogenous factors. The presence of vitamin $C$ and/or animal tissue (so-called meat factor, MF) in dietary intake was determined to increase the bioavailability of ionic iron. Among the endogenous factors that can improve the bioavailability of non-haem iron, duodenal cytochrome b (Dcytb) and ascorbic acid released actively by gastric cells are listed [20]. Interestingly, research has shown that in the presence of a full volume of gastric content the bioavailability of dietary iron is markedly higher than in the sole presence of isolated hydrochloric acid $[21,22]$.

The absorption of iron is limited by oxalates, phytates, polyphenols, phosphates, and calcium. Therefore, certain food products, such as milk and dairy products, eggs, coffee, tea, spinach, dry legume seeds (i.e. rich sources of the abovementioned components), hinder the utilisation of dietary iron. Hence, the bioavailability of non-haem iron varies and can be determined inter alia by dietary composition $[3,19]$. Apart from the dietary factors mentioned above, the bioavailability of non-haem iron can be, to a large extent, impaired by pathological conditions of the alimentary tract, such as Helicobacter pylori (H. pylori) infection. The results of many recently published studies point to the association between $H$. pylori infection and iron deficiency anaemia (IDA) [23-28]. Special attention should be paid to the reported cases of iron deficiency anaemia concomitant to $H$. pylori infection, in which anaemia was the only symptom of the infection $[29,30]$. The association between $H$. pylori infection and impaired absorption of iron is also corroborated by the documented improvement of haematological parameters after complete elimination of the bacterium [25, 28, 31-33].

Previous studies identified the main pathways by which $H$. pylori can modulate the bioavailability of dietary iron. The first pathway is associated with the infection-induced changes in the composition of gastric juice, and the second is the result of the ability of H. pylori to obtain iron from the host's body [34-37]. Helicobacter pylori infection results in active gastritis and atrophic inflammation of gastric mucosa, which can be followed by hypoacidity or achlorhydria [38-40]. Capurso et al. discovered that the $\mathrm{pH}$ of gastric juice in pa- tients in whom $H$. pylori infection was concomitant with sideropenic anaemia $(\mathrm{pH}=5.7)$ is significantly higher than in subjects with $H$. pylori-induced gastritis without co-existing anaemia ( $\mathrm{pH}=2.0)$ [41]. According to the authors, this phenomenon could result from decreased gastric secretion of ascorbic acid and hydrochloric acid, which might develop secondarily to the $H$. pylori infection [41, 42]. Available evidence suggests that the presence of endogenous ascorbic acid is necessary for the absorption of trivalent iron. Moreover, this interaction is known to be effective solely in the presence of hydrochloric acid [21, 22]. Ascorbic acid was determined to reduce ferric ions $\mathrm{Fe}^{3+}$ to ferrous ions $\mathrm{Fe}^{2+}$ (absorbed by absorptive enterocytes), a process which depends on the presence of acidic $\mathrm{pH}$ [43]. Furthermore, soluble monomeric forms of ascorbic acid can form chelate complexes with the trivalent iron ions, thereby decreasing polymerisation and precipitation of the latter. Iron ion chelation by ascorbic acid occurs solely in acidic environments $(\mathrm{pH}<3)$ [43].

While discussing the role of $H$. pylori in the pathogenesis of sideropenic anaemia, one should remember that iron constitutes the principal growth factor for this pathogen. Consequently, H. pylori (as well as other bacteria) has developed highly effective mechanisms of iron absorption, and competes with the host for iron. Helicobacter pylori can synthesise a superficial $70 \mathrm{kDa}$ protein, which binds the host's iron-sequestrating proteins and is involved in direct uptake of this nutrient $[36,37]$. Limited availability of iron in a growth medium was identified as a factor inducing the expression of this receptor on a microbial surface [44]. The abovementioned data seem to explain the higher incidence of sideropenic anaemia concomitant to $H$. pylori infection that was documented in many studies involving subjects at risk of developing iron deficiency, i.e. among women at reproductive age, children, and adolescents $[45,46]$.

The transport of reduced $\mathrm{Fe}^{2+}$ ions into the cytoplasm of enteric cells is mediated by DMT1 (divalent metal transporter) protein expressed in the apical membrane of mature enterocytes [3, 19, 47]. The regulation of non-haem iron absorption is a subject of extensive ongoing research. HFE (high Fe, human hemochromatosis protein) is one of the proteins involved in monitoring iron concentration and the absorption of this nutrient $[19,47]$. HFE is expressed on the basal membrane of enterocyte crypts, where it forms complexes with $\beta_{2}$-microglobulin and transferrin receptor ( $\beta_{2}$ M-HFE-TfR1) $[19,47,48]$. The interaction between these three proteins is believed to affect the reception of information on the processes of iron utilisation, i.e. on the intensity of erythropoiesis and liver metabolism of iron [19]. Fur- 
thermore, the degree of absorption is also modulated by regulatory substances, indicating the actual iron levels in tissue deposits. An inverse correlation was documented between the concentration of ferritin and the absorption of non-haem iron [3, 49]. A similar relation was observed in the case of haem iron; however, an increased accumulation of this form of iron only slightly reduced its absorption. Hepcidin seems to be the key mediator responsible for the regulation of iron accumulation [48, 50, 51].

Hepcidin is a short, cysteine-rich peptide with a molecular weight of 2-3 kDa, synthesised mostly by hepatocytes, circulating in serum, and eliminated with urine [52]. The expression of hepcidin gene is regulated on a transcriptional level [53]. Two principal pathways of cellular signalling involved in the transcription of hepcidin have been identified to date. The first is associated with the activation of cytoplasmic transcription proteins Stat3 (signal transducer and activator of transcription). Upon activation, these proteins are transferred into the nucleus where they activate transcription of the hepcidin gene, binding to a relevant sequence of DNA. Pro-inflammatory cytokines, especially interleukin-6, induce the process of hepcidin gene transcription through the activation of Stat3 and its subsequent binding to the regulatory region of hepcidin promoter [53-55]. The second mechanism of hepcidin transcription control (depending on BMP/Smad signalling pathway) involves Smad proteins (their name is a combination of the names of two homologous proteins: Sma and MAD) and bone morphogenetic proteins (BMPs) [53-55]. BMPs are pleotropic signal molecules from the transforming growth factor family [53]. Binding BMP to their type II and type I receptors (BMP-type I/ type II) results in the phosphorylation of intracellular protein RSmad, which subsequently binds to Smad4 (also referred to as Co-Smad) [53]. The resultant complex (RSmad-Smad4) is transferred into the nucleus and (together with other transcription factors) activates its target genes, including the hepcidin gene [53]. The list of factors that can affect the expression of hepcidin on post-translational levels includes iron, anaemia, hypoxia, and inflammation [56-62].

The role of hepcidin in the regulation of the bioavailability of dietary iron is associated with its interaction with transmembrane protein, ferroportin (Fpn) [63]. Ferroportin is expressed on the surface of all cells that can release iron into circulation, i.e. absorptive enterocytes, macrophages, and hepatocytes, as well as on the surface of placental cells [63]. The biological role of Fpn is the transportation of iron from cells to blood vessels. Hepcidin regulates the expression of ferroportin on a post-translational level $[63,64]$. It can directly bind to Fpn molecules, with subsequent internalisation of the resultant hepcidin-ferroportin complex. Ferroportin undergoes lysosomal degradation inside the endosome. Its loss from the cellular surface induces a secondary decrease in the release of iron from the cell $[63,64]$. Consequently, the interaction between hepcidin and ferroportin inhibits the efflux of iron ions from enterocytes to blood vessels [65-69]. Whenever the systemic deposits of iron are either sufficient or too high, the liver synthesis of hepcidin is enhanced; the hormone is released into circulation, reaches enterocytes, and binds to ferroportin, thereby inducing its endocytosis and degradation $[65,69-71]$. A reduction of iron deposits is associated with an opposite phenomenon: decreased synthesis of hepcidin in hepatocytes, and the involvement of Fpn molecules present on the basolateral membranes of enterocytes in the export of iron to the vascular bed $[48,50,51,64]$.

\section{References}

1. Anderson GJ, Frazer DM, McKie AT, et al. Mechanisms of haem and non-haem iron absorption: lessons from inherited disorders of iron netabolism. BioMetals 2005; 4: 339-48.

2. Romanowski T, Sikorska K, Bielawski KP. Molecular basis of hereditary hemochromatosis [Polish]. Postępy Hig Med Dośw 2006; 60: 217-26.

3. Lynch S. Iron metabolism. In: Nutritional anemia. Badham J, Zimmermann MB (eds.). SIGHT AND LIFE, Sweden 2007; 59-76.

4. Baranowski WJ. The role of intestinal mucus in absorbing iron [Polish]. Gastroenterol Pol 1999; 6: 63-5.

5. Baranowski WJ. Iron absorption - unknown properties of gastric mucins [Polish]. Pediatr Współcz 2005; 7: 281-4.

6. Baronowski WJ. Iron deficiency anemia - new insight into old facts [Polish]. Gastroenterol Pol 2005; 12: 253-6.

7. Latunde-Dada GO, Simpson RJ, McKie AT. Recent advances in mammalian haem transport. Trends Biochem Sci 2006; 3 : 182-8.

8. Shayeghi M, Latunde-Dada GO, Oakhill JS, et al. Identification of an intestinal heme transporter. Cell 2005; 122: 789-801.

9. West AR, Oates PS. Mechanisms of heme iron absorption: current questions and controversies. World J Gastroenterol 2008; 14: 4101-10.

10. Łoboda A, Jazwa A, Grochot-Przeczek A, et al. Heme oxygenase- 1 and the vascular bed: from molecular mechanisms to therapeutic opportunities. Antioxid Redox Signal 2008; 10: 1767-812.

11. Ryter SW, Alam J, Choi AM. Heme oxygenase-1/carbon monoxide: from basic science to therapeutic applications. Physiol Rev 2006; 86: 583-650.

12. Kaur H, Hughes MN, Green CJ, et al. Interaction of bilirubin and biliverdin with reactive nitrogen species. FEBS Lett 2003; 543: 113-9.

13. Otterbein LE, Bach FH, Alam J, et al. Carbon monoxide has anti-inflammatory effects involving the mitogen-activated protein kinase pathway. Nat Med 2000; 6: 422-8. 
14. Otterbein LE, Zuckerbraun BS, Haga M, et al. Carbon monox ide suppresses arteriosclerotic lesions associated with chronic graft rejection and with balloon injury. Nat Med 2003; 9: 183-90.

15. Brouard S, Otterbein LE, Anrather J, et al. Carbon monoxide generated by heme oxygenase 1 suppresses endothelial cell apoptosis. J Exp Med 2000; 192: 1015-26.

16. Suttner DM, Dennery PA. Reversal of HO-1 related cytoprotection with increased expression is due to reactive iron. FASEB J 1999; 13: 1800-9.

17. Thom SR, Fisher D, Xu YA, et al. Adaptive responses and apoptosis in endothelial cells exposed to carbon monoxide. Proc Natl Acad Sci USA 2000; 97: 1305-10.

18. West AR, Oates PS. Subcellular location of heme oxygenase 1 and 2 and divalent metal transporter 1 in relation to endocytotic markers during heme iron absorption. J Gastroenterol Hepatol 2008; 23: 150-8.

19. Kimberly K, Bonkowsky HL. Heme oxygenase: recent advances in understanding its regulation and role. Proc Assoc Am Phys 1999; 111: 438-47

20. Bezwoda W, Charlton RW, Bothwell T, et al. The importance of hydrochloridric acid in the absorption of nonheme food iron. J Lab Clin Med 1978; 92: 108-16.

21. Sobala GM, Schorah CJ, Sanderson M, et al. Ascorbic acid in the human stomach. Gastroenterology 1989; 97: 357-63.

22. Lombard M, Chua E, O'Toole P. Regulation of intestinal nonhaem iron absorption. Gut 1997; 40: 435-9.

23. Ciacci C, Sabbatini F, Cavallaro R, et al. Helicobacter pylori impairs iron absorption in infected individuals. Dig Liver Dis 2004; 36: 455-60.

24. Afifi MT, Abd El-Aziz HK, Hamed NA, et al. Role of Helicobacter pylori in refractory iron deficiency anaemia. Br J Biomed Sci 2009; 66: 133-6.

25. Pérez Roldán F, Castellanos Monedero JJ, González Carro P, et al. Effect of Helicobacter pylori eradication on iron deficiency anemia of unknown origin. Gastroenterol Hepatol 2008; 31: 213-6.

26. Fayed SB, Aref MI, Fathy HM, et al. Prevalence of celiac disease, Helicobacter pylori and gastroesophageal reflux in patients with refractory iron deficiency anemia. J Trop Pediatr 2008; 54: 43-53.

27. Hershko C, Ronson A. Iron deficiency, Helicobacter infection and gastritis. Acta Haematol 2009; 122: 97-102.

28. Huang X, Qu X, Yan W, et al. Iron deficiency anaemia can be improved after eradication of Helicobacter pylori. Postgrad Med J 2010; 86: 272-8.

29. Carnicer J, Badia R, Argemi J. Helicobacter pylori gastritis and sideropenic refractory anemia. J Pediatr Gastroenterol Nutr 1997; 25: 441

30. Parkinson AJ, Gold BD, Bulkow L, et al. High prevalence of Helicobacter pylori infection in the Alaska native population and association with low serum ferritin levels in young adults. Clin Diagn Lab Immunol 2000; 7: 885-8.

31. Choe YH, Kwon YS, Jung MK, et al. Helicobacter pylori-associated iron-deficiency anemia in adolescent female athletes. J Pediatr 2001; 139: 100-4.

32. Sugiyama T, Tsuchida M, Yokota K, et al. Improvement of long-standing iron-deficiency anemia in adults after eradication of Helicobacter pylori infection. Intern Med 2002; 41: 491-4.
33. Annibale B, Marignani M, Monarca B, et al. Reversal of iron deficiency anemia after Helicobacter pylori eradication in patients with asymptomatic gastritis. Ann Intern Med 1999; 131: 668-72.

34. Sobala GM, Schorah CJ, Shires S, et al. Effect of eradication of Helicobacter pylori on gastric juice ascorbic acid concentrations. Gut 1993; 34: 1038-41.

35. Annibale B, Capurso G, Delle Fave G. Consequences of Helicobacter pylori infection on the absorption of micronutrients. Dig Liver Dis 2002; 34: S72-7.

36. Leontiadis GI, Sharma VK, Howden CW. Non-gastrointestinal tract associations of Helicobacter pylori infection. Arch Intern Med 1999; 159: 925-40.

37. Worst DJ, Otto BR, de Graaff J. Iron-repressible outer membrane proteins of Helicobacter pylori involved in heme uptake. Infect Immun 1995; 63: 4161-5.

38. Goldstone AR, Quirk PH, Dixon MF. Helicobacter pylori infection and gastric cancer. J Pathol 1996; 179: 129-37.

39. Gutierrez O, Melo M, Segura AM, et al. Cure of Helicobacter pylori infection improves gastric acid secretion in patients with corpus gastritis. Scand J Gastroenterol 1997; 32: 664-8.

40. Bock OAA, Richards WCD, Witts LJ. The relationship between acid secretion after augmented histamine stimulation and the histology of gastric mucosa. Gut 1963; 4: 112-4.

41. Capurso G, Lahner E, Marcheggiano A, et al. Involvement of corporal mucosa and related changes in gastric acid secretion characterize patients with iron deficiency anaemia with Helicobacter pylori infection. Aliment Pharmacol Ther 2001; 15: 1753-61.

42. Annibale B, Capurso G, Lahner E, et al. Concomitant alterations in intragastric $\mathrm{pH}$ and ascorbic acid concentration in patients with Helicobacter pylori gastritis and associated iron deficiency anaemia. Gut 2003; 52: 496-501.

43. Dickey W. Iron deficiency, gastric atrophy and Helicobacter pylori. Dig Liver Dis 2002; 34: 313-5.

44. Andrews SC, Robinson AK, Rodriguez-Quinones F. Bacterial iron homeostasis. FEMS Microbiol. Rev 2003; 27: 215-37.

45. Mulayim B, Celik NY, Yanik FF. Helicobacter pylori infection detected by 14C-urea breath test is associated with iron deficiency anemia in pregnant women. J Obstet Gynaecol Res 2008; 34: 980-5.

46. Peach HG, Bath NE, Farish SJ. Helicobacter pylori infection: an added stressor on iron status of women in the community. Med J Austr 1998; 69: 188-90.

47. Ludwiczek S, Theurl I, Artner-Dworzak E, et al. Duodenal HFE expression and hepcidin levels determine body iron homeostasis: modulation by genetic diversity and dietary iron availability. J Mol Med 2004; 82: 373-82.

48. Wessling-Resnick M. A possible link between hepcidin and regulation of dietary iron absorption. Nutr Rev 2002; 60: 371-4.

49. Roughead ZK, Hunt JR. Adaptation in iron absorption: iron supplementation reduces nonheme-iron but not heme-iron absorption from food. Am J Clin Nutr 2000; 72: 982-9.

50. Ganz T. Hepcidin and its role in regulating systemic iron metabolism. Hematology 2006; 1: 29-35.

51. Robson KJ. Hepcidin and its role in iron absorption. Gut 2004; 53: 617-9. 
52. Kemna EH, Tjalsma H, Podust VN, et al. Mass spectrometry-based hepcidin measurements in serum and urine: analytical aspects and clinical implications. Clin Chem 2007; 53: 620-8.

53. Domenico I, Ward DM, Kaplan J. Hepcidin regulation: ironing out the details. J Clin Invest 2007; 117: 1755-8.

54. Pietrangelo A, Dierssen U, Valli L, et al. STAT3 is required for IL-6-gp130-dependent activation of hepcidin in vivo. Gastroenterology 2007; 132: 294-300.

55. Verga Falzacappa MV, Spasic MV, Kessler R, et al. STAT-3 mediates hepatic hepcidin expression and its inflammatory stimulation. Blood 2007; 109: 353-8.

56. Benedict C, Ghio AJ, Gehring H, et al. Transient hypoxia and downregulation of circulating prohepcidin concentrations in healthy young men. Haematologica 2007; 92: 125-6.

57. Kemna EHJM, Pickkers P, Nemeth E, et al. Time-course analysis of hepcidin, serum iron, and plasma cytokine levels in humans injected with LPS. Blood 2005; 106: 1864-6.

58. Leung PS, Srai SK, Mascarenhas M, et al. Increased duodenal iron uptake and transfer in a rat model of chronic hypoxia is accompanied by reduced hepcidin expression. Gut 2005; 54 : 1391-5.

59. Nemeth E, Valore EV, Territo $M$, et al. Hepcidin, a putative mediator of anemia of inflammation, is a type II acute-phase protein. Blood 2003; 101: 2461-3.

60. Nicolas G, Bennoun M, Porteu A, et al. Severe iron deficiency anemia in transgenic mice expressing liver hepcidin. Proc Natl Acad Sci USA 2002; 99: 4596-601.

61. Nicolas G, Chauvet C, Viatte L, et al. The gene encoding the iron regulatory peptide hepcidin is regulated by anemia, hypoxia, and inflammation. J Clin Invest 2002; 110: 1037-44.

62. Pigeon C, Ilyin G, Courselaud B, et al. A new mouse liver-specific gene, encoding a protein homologous to human antimicrobial peptide hepcidin, is overexpressed during iron overload. J Biol Chem 2001; 276: 7811-9.

63. Nemeth E, Tuttle MS, Powelson J, et al. Hepcidin regulates cellular iron efflux by binding to ferroportin and inducing its internalization. Science 2004; 306: 2090-3.

64. Knutson MD, Oukka M, Koss LM, et al. Iron release from macrophages after erythrophagocytosis is up-regulated by ferroportin 1 overexpression and down-regulated by hepcidin. Proc Natl Acad Sci U S A 2005; 102: 1324-8.

65. Laftah AH, Ramesh B, Simpson RJ, et al. Effect of hepcidin on intestinal iron absorption in mice. Blood 2004; 103: 3940-4.

66. Luft FC. Hepcidin comes to the rescue. J Mol Med 2004; 82: 345-7.

67. Nicolas G, Bennoun M, Devaux I, et al. Lack of hepcidin gene expression and severe tissue iron overload in upstream stimulatory factor 2 (USF2) knockout mice. Proc Natl Acad Sci U S A 2001; 98: 8780-5.

68. Nicolas G, Bennoun M, Porteu A, et al. Severe iron deficiency anemia in transgenic mice expressing liver hepcidin. Proc Natl Acad Sci USA 2002; 99: 4596-601.

69. Yamaji S, Sharp P, Ramesh B, et al. Inhibition of iron transport across human intestinal epithelial cells by hepcidin. Blood 2004; 104: 2178-80.

70. Nemeth E, Preza GC, Jung CL, et al. The N-terminus of hepcidin is essential for its interaction with ferroportin: structure-function study. Blood 2006; 107: 328-33.
71. Nemeth E, Rivera S, Gabayan V, et al. IL-6 mediates hypoferremia of inflammation by inducing the synthesis of the iron regulatory hormone hepcidin. J Clin Invest 2004; 113: 1271-6.

Received: 10.01 .2012

Accepted: 25.11.2012 